„Produkte des LGRB - gestern, heute und morgen" (vgl. Foto).

Zuhörerlnnen waren neben wenigen Mitgliedern der Sektion Süd baden vor allem auch Mitglieder aus der Sektion Stuttgart, die im Breisgau auf Exkursion waren, genauer formuliert in Freiburg (LGRB), in Breisach, Neu-Brisach und Sasbach. Am Samstag, den 10. Mai, traf man sich wieder mit den Exkursionsmitgliedern der Sektion Stuttgart: Diesmal am wissenschaftlichen Lehrpfad am Limberg bei Sasbach (am Rhein). Die Führenden waren der Kaiserstuhl-

Gästeführer Dipl.-Kartograph Gerhart Seeger (vgl. Foto) (Sektion Südbaden) und Dipl.-Forstwirt Thomas Huth (LGRB). An mehreren Stationen erfuhr man Interessantes über Geologie, Geschichte, Vegetation,

Am 22. Mai folgte nun schon die nächste Veranstaltung: eine Führung durch die Sonderausstellung „Baustelle Gotik" im Augustiner Museum in Freiburg. Anlass der sehr sehenswerten Ausstellung war das 500-jährige Weihejubiläum des Chors im Freiburger Münster. Es gab in den wichtigen Zeiten des Freiburger Münsters 60 ortsansässige Präsenzpriester, jeder mit eigenem Altar oder eigener Kapelle! In der Ausstellung waren sehr anschaulich die verschiedenen Berufsstände und Handwerkstechniken ausgestellt, die beim Bau des Münsters beteiligt waren bzw. angewendet wurden: Zimmermann, Steinmetz, Eisenverarbeitung,

Glasmaler, ... Neben der Handwerksgeschichte erfuhr man auch Wissenswertes über Hans Niesenberger aus Graz, der ab 1471 Baumeister war und nach einem Fehler beim Bau 1491 einen Auflösungsvertrag erhielt. Außerdem war interessant, dass die Idee des durchbrochenen Maßwerkturmhelms vermutlich aus Straßburg stammt (Erwin von Steinbach?). Sehr anschaulich informiert und tief beeindruckt traf man sich danach zum traditionellen Spargelessen - diesmal wieder in der Freiburger Altstadt.

Nach der Sommerpause ging es dann weiter mit Herrn Dipl.-Hydrol.
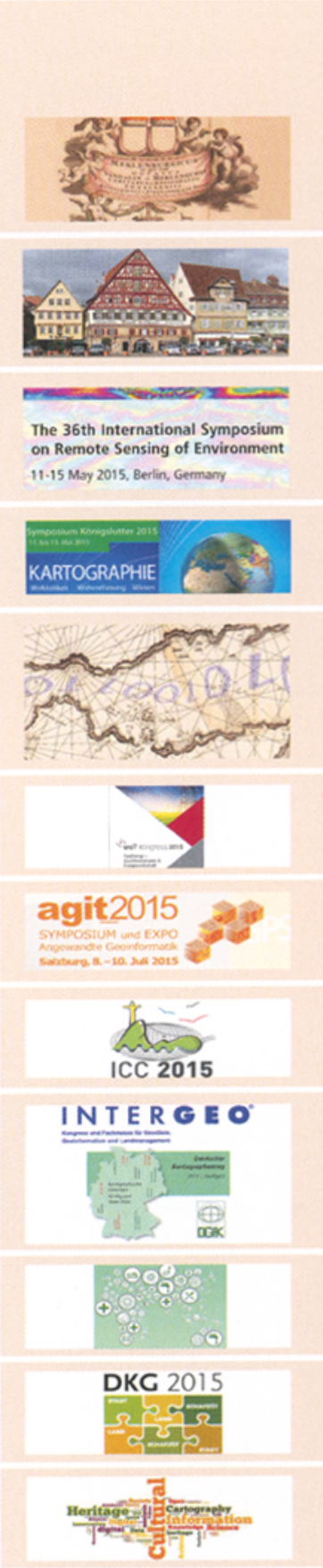

\section{ICA European Symposium on}

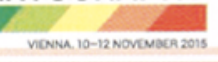
2016

14. bis 16. Juni 2016, Potsdam

64. Deutscher Kartographentag

Deutsche Gesellschaft für Kartographie. Internetadresse demnächst

11. bis 13. Oktober 2016, Hamburg

Intergeo 2016

DVW Gesellschaft für Geodäsie, Geoinformation und Landmanagement e. V. Internetadresse demnächst

\section{7}

2. bis 7. Juli 2017, Washington, USA

$2^{\text {th }}$ International Cartographic Conference

International Cartographic Association (ICA). http://www.icc2017.org/ 